\title{
Perspectiva europea sobre los riesgos laborales en el ámbito del teletrabajo
}

European Perspective on Occupational Hazards in Teleworking

\section{William Cockburn ${ }^{1}$ \\ Miren Hurtado ${ }^{1}$}

${ }^{1}$ Agencia Europea para la Seguridad y la Salud en el Trabajo (EU-OSHA), Bilbao, España.

Fechas · Dates

Recibido: 2021.02 .02

Aceptado: 2021.02.04

Publicado: 2021.04.15
Correspondencia · Corresponding Author

William Cockburn

cockburn@osha.europa.eu 
Tras la declaración oficial de la COVID-19 como pandemia por la Organización Mundial de la Salud en marzo de 2020, los Estados Miembros de la Unión Europea pusieron en marcha una serie de medidas para contener y frenar la expansión del virus en los lugares de trabajo. La naturaleza y el alcance de las restricciones difieren entre Estados y sectores. La crisis de la COVID-19 también ha forzado a las empresas a aplicar nuevos procedimientos y prácticas en muy poco tiempo o, en algunos casos, a suspender su trabajo y actividades económicas.

Las prácticas impuestas implican, en primer lugar, realizar una evaluación de los riesgos y, después, una aplicación de la jerarquía de medidas preventivas. Esto significa aplicar primero medidas de control para eliminar la fuente del riesgo y, si esto no fuera posible, minimizar la exposición de la plantilla a la COVID-19 a través de medidas de sustitución, por ejemplo, a través del teletrabajo. Su implantación como norma ha sido una medida generalizada adoptada por muchas empresas y organizaciones que incluso, visto el avance y desarrollo de la pandemia, pueden llegar a contemplarlo y adoptarlo como una práctica de trabajo moderna y a largo plazo.

En el contexto de restricciones en la movilidad y confinamiento en algunos países, millones de personas en Europa se han visto obligadas a trabajar desde su domicilio a tiempo completo para minimizar el riesgo de contraer el virus ${ }^{(1)}$. El teletrabajo tiene un impacto en la seguridad y salud en el trabajo y tanto la gerencia de la empresa como su plantilla deben ser conscientes de los riesgos asociados y abordarlos mediante la implantación de medidas de prevención y control adecuadas para evitar el impacto en nuestra salud física y mental. Los largos períodos de trabajo sedentario, la falta de ejercicio físico, el trabajo en soledad, los difusos límites entre el trabajo remunerado y la vida privada y el estrés son algunos de los riesgos que encierra el teletrabajo y que pueden afectar a la salud musculoesquelética y mental de las personas trabajadoras.

Idealmente, el teletrabajo se ha de llevar a cabo en la casa de la persona trabajadora en una habitación aislada acústica y visualmente, con suficiente luz y con el equipamiento adecuado. La empresa puede recordar por correo electrónico las condiciones ideales a nivel ergonómico, presentar de manera detallada los sistemas de recursos humanos y establecer horarios flexibles para facilitar la conciliación, dependiendo de cada caso individual, así como proveer un espacio dentro de la organización que cumpla con las recomendaciones de salud cuando el teletrabajo no fuera posible.

Otras líneas de actuación por parte de la empresa incluyen recordar a la plantilla la importancia de desconectarse después del horario laboral para prevenir el "presentismo remoto" y ofrecerles medidas de apoyo para el uso de herramientas digitales, facilitando el acceso de forma remota a todas las aplicaciones necesarias y proporcionando tutoriales en línea si fuera necesario(2). En este sentido, existen una variedad de herramientas prácticas y materiales de orientación desarrollados en la UE y a nivel nacional(3). El proyecto europeo OiRA ${ }^{(4)}$ (Online interactive Risk Assessment por sus siglas en inglés) es una plataforma web desarrollada por la EU-OSHA que permite la creación de herramientas nacionales de evaluación de 
riesgos sectoriales para las pequeñas y medianas empresa en cualquier idioma y de un modo fácil y normalizado. Se trata de la primera iniciativa de ámbito europeo concebida para alentar a las pymes europeas a evaluar los riesgos (principalmente, a través de los Estados Miembros y los/as agentes sociales - sindicatos y empresariado - a escala comunitaria y nacional).

Durante la pandemia, EU-OSHA creó la herramienta "OiRA para la COVID-19"(5), basada en pautas no vinculantes, con el objetivo de ayudar a las empresas a continuar siendo un entorno laboral seguro y saludable que ha cambiado de forma significativa en muy poco tiempo. La herramienta solo proporciona asesoramiento genérico, ya que las situaciones difieren de un país a otro y de un sector a otro. Por lo tanto, es fundamental obtener información actualizada de las autoridades públicas sobre la prevalencia de la COVID-19 en cada país y área.

El Instituto Nacional de Seguridad y Salud en el Trabajo publicó unas recomendaciones ${ }^{(6)}$ para la prevención de riesgos psicosociales en situación de trabajo a distancia dirigidas al personal de gerencia de las empresas. Se destaca la necesidad de tener un conocimiento de la COVID-19(7) para la organización efectiva del trabajo y de empatizar con la plantilla protegiéndoles de la incertidumbre laboral, a través de una comunicación asertiva que incluya información actualizada, veraz y precisa sin estigmatizar a las personas que se hayan podido ver afectadas por el virus. También se han de tener en cuenta las limitaciones (convivencia, confinamientos, espacios compartidos, etc.) que el hogar tiene como espacio de trabajo no habitual. Se recomienda transmitir a la plantilla pautas como la planificación diaria de la jornada, la actividad y el ejercicio físico, el reconocimiento y aceptación de las emociones, así como buscar apoyo y pedir ayuda profesional si fuera necesario ${ }^{(8)}$.

La experiencia adquirida durante la pandemia también ha servido para desarrollar una política y unos procedimientos de teletrabajo o revisar los existentes en materia de teletrabajo. En el ámbito legislativo europeo, el Acuerdo Marco Europeo sobre Teletrabajo de $2002^{(9)}$ ofrece orientación sobre la organización del trabajo a distancia, estableciendo el concepto de "soberanía del tiempo". Esta denominación hace referencia a la plantilla teletrabajadora como gestora principal de su tiempo durante la jornada laboral. En España, la entrada en vigor del Real Decreto-ley del 22 de septiembre de $2020^{(10)}$ pasó a regular el trabajo a distancia en todo el país.

En el actual contexto de la pandemia COVID-19, la generalización del teletrabajo está siendo una medida preventiva muy común y normalizada en empresas de toda Europa hasta el punto de que muchas pueden contemplar su implementación a largo plazo. Respecto al ámbito regulatorio, la pandemia ha puesto de manifiesto la necesidad de un nuevo marco europeo sobre teletrabajo y algunos Estados Miembros como España han aprobado recientemente legislación para su regulación. 


\section{Bibliografía}

1. Consulte nuestros consejos prácticos sobre el teletrabajo desde casa y la protección de la salud. Bilbao: EU-OSHA [acceso 2 feb 2021]. Disponible en: https:// osha.europa.eu/es/highlights/check-out-our-practical-tips-home-based-teleworkand-protect-your-health

2. Travail sur écran. París: INRS [acceso 1 feb 2021]. Disponible en: http://www. inrs.fr/risques/travail-ecran/ce-qu-il-faut-retenir.html

3. Telework in the EU before and after the COVID-19: where we were, where we head to. Bruselas: Comisión Europea [acceso 2 feb 2021]. Disponible en: https:// ec.europa.eu/jrc/sites/jrcsh/files/jrc120945_policy_brief_-_covid_and_telework_final.pdf

4. Online interactive Risk Assessment. Bilbao: EU-OSHA [acceso 2 feb 2021]. Disponible en: https://oiraproject.eu/es/what-oira

5. Herramienta OiRA de evaluación de riesgos de la COVID-19 [acceso 2 feb 2021]. Disponible en: https://oiraproject.eu/oira-tools/eu/covid-19/covid-19/++session++1164329/@@start?initial_view=1\&new_session=1

6. Prevención de riesgos psicosociales en situación de trabajo a distancia debida al COVID-19. Recomendaciones para el empleador. Madrid: INSST [acceso 2 feb 2021]. Disponible en: https://www.insst.es/documents/94886/712882/ Riesgos+psicosociales+y+trabajo+a+distancia+por+Covid-19.+Recomendaciones+para+el+empleador.pdf/70cb49b6-6e47-49d1-8f3c-29c36e5a0d0f

7. Preguntas y respuestas sobre el nuevo coronavirus (COVID-19). Madrid: Ministerio de Sanidad, Consumo y Bienestar Social [acceso 2 feb 2021]. Disponible en: https://www.mscbs.gob.es/profesionales/saludPublica/ccayes/alertasActual/ nCov/documentos/20200326_Preguntas_respuestas_2019-nCoV.pdf

8. Teleworking during the COVID-19 pandemic and beyond. Ginebra: OIT [acceso 2 feb 2021]. Disponible en: https://www.ilo.org/wcmsp5/groups/public/--ed_protect/--protrav/---travail/documents/instructionalmaterial/wcms_751232.pdf

9. El Teletrabajo. Bruselas: Unión Europea [acceso 2 feb 2021]. Disponible en: https://eur-lex.europa.eu/legal-content/ES/TXT/?uri=LEGISSUM\%3Ac10131

10. Real Decreto-ley de trabajo a distancia. RDL. No 28/2020 (22 sep 2020). 